\title{
The moisture distribution in partially saturated concrete studied by impedance spectroscopy.
}

\author{
I. Sánchez*, C. Antón, G. de Vera, J.M. Ortega, M.A. Climent.
}

Departament d'Enginyeria de la Construcció, Obres Públiques i Infraestructura Urbana, Universitat d'Alacant, Ap. Correus 99, 03080, Alacant/Alicante, Spain.

* Corresponding author: Phone +34965903400 Ext 2090, Fax +34965903678, Email Isidro.Sanchez@ua.es

\begin{abstract}
The moisture content and the distribution of that moisture have a great influence on the durability properties of concrete structures. Several non-destructive techniques have been used for the determination of the total water content, but the moisture distribution is difficult to determine. In this work is presented the use of impedance spectroscopy to study the water distribution in samples of concrete with controlled and homogeneously distributed moisture. The technique is suitable for the determination of the water distribution inside the sample, using the appropriate equivalent circuits, and it shows that with the selected drying procedures there is no change in the solid phase of the samples, though for this purpose the technique can only be used to study variations in the solid phase qualitatively when samples are too thick. The water tends to redistribute homogeneously forming a continuous path all over the pore walls, while there is enough water inside the sample. This result is very important since it is a first step for the study of the moisture distribution in real structures, usually partially saturated.
\end{abstract}

Keywords: Impedance Spectroscopy; saturation degree; moisture distribution;

\section{1.- Introduction.}

Moisture content in concrete plays an essential role in different deterioration processes, such as alkali-aggregate reaction [1] and freeze-thawing damage [2]. 
Moisture is also one of the main factors that can control the corrosion rate of reinforcing bars in reinforced or prestresed structures [3]. It is also well know the effect that the saturation degree of concrete has on the transport of aggressive substances into concrete such as $\mathrm{CO}_{2}$ [4] and chlorides [5-7], and also has an important influence on the water uptake of concrete structures [8], and this water can have aggressive substances.

This is the reason why many techniques have been used to determine, preferably using non-destructive methodologies, the moisture content of concrete samples [911], as well as the modifications that happen during the drying -wetting processes. The review by Parrott [9] suggests many techniques, some of them destructive, such as oven drying, but most of the techniques reviewed are nondestructive. They include the measurement of the resistivity. It is well known the relationship among electrical conductivity (or resistivity) of concrete with the water content of this material $[3,12,13]$. The review also includes the measurement of the dielectric properties, in the very high frequency region (1-100 GHz) [14]. In this region the water can also be distinguished from the solids in concrete. This is the basis for the use of the georadar to study the content of water in concrete $[10,11,16]$, and some other techniques such as thermal conductivity [16-21], infrared absorption [17], and neutron scattering [18]. Most of them allow the determination of free water, and some distinguish the moisture gradients in a non-saturated sample.

But not only the total amount of water or the moisture gradients are important. For the durability of the structures, especially regarding the chloride ingress, the distribution of water is a very important factor because the main diffusion of chlorides is through the aqueous phase [19]. 
The impedance spectroscopy (IS) has been proved to be a technique that can be used to study the microstructure of cementitious materials in several conditions, and with different applications [20-23] .The main advantage of the technique is that it is non-destructive and allows to follow the modifications that can take place in the same material. The main advantage of using this technique, for this particular work, is that it is very sensitive, not only to the total amount of water [20], but also to the presence or absence of water in some pores that can vary as a function of the mechanical load applied [24], what means that the impedance spectroscopy can be suitable to detect the presence or absence of water in pores of a cement based material. Those determinations were made on samples kept in a $100 \%$ RH. No previous work has been found on partially saturated concrete samples, with controlled percentage of saturation.

The technique has been widely explained [25] and is based on the fact that different phenomena that take place in a material, with its own time constant will respond at a given frequency. It is essential to select properly the frequency range where the measurement is taken. In a material like concrete, with two phases, one liquid and other solid, the measurement should be taken in a frequency range from the $\mathrm{kHz}$ to the $\mathrm{MHz}$ [20]. The equivalent circuits used for the fitting of the experimental data have evolved with time. Initially there were proposed circuits that contained only one time constant [26, 27],but the experience showed that there are two time constants in the frequency range used for the determination of the dielectric properties[28, 29], and the presence of two time constants has been proved numerically [20]. One of these time constants has been related to the electrolyte in the pore network of concrete. It has also been established that the amount of solid-electrolyte interface can be studied using the appropriate equivalent circuit [30]. These are the reasons why the IS is considered a promising 
technique in the field of the non-destructive determination, not only of the total amount of water, but also the moisture distribution inside the pore network of concrete.

So the objective of this work is to study the influence of the water content in the dielectric response of samples of three different concretes in the frequency range from $100 \mathrm{~Hz}$ to $100 \mathrm{MHz}$. The samples were previously conditioned, and they had time enough to eliminate the moisture gradients due to the laboratory drying by a natural redistribution of water. The reason for this redistribution of water was, on one hand to investigate the effect of the total amount of water, avoiding wet and dried regions that could hide some information about dielectric properties of the material. On the other hand, these conditions are more similar to real structures exposed to an average relative humidity in a real environment, where the structures will be serving. Due to the electric nature of the IS technique it is reasonable to expect obtaining information about the distribution of the electrolyte, especially due to the electric nature of the technique and the capacity to study the interface solid-electrolyte.

\section{2.- Experimental setup.}

\section{1.- Sample preparation}

Three different concrete dosages were used for the samples. The dosages are shown in Table 1. The concretes will be called H1, H2 and H3 from now on, according to the different dosages used, as defined in Table 1 . The cement used was Ordinary Portland Cement (CEM I 42,5R), according to the Spanish standard), the aggregates used were of calcareous nature, and the plasticizer used was modified polycarboxylate. As it is shown in Table 1, three water to cement ratios (w:c, mass of water per mass of cement) have been used, form 0.6 to 0.38 . 
Table 2 shows the results of compressive strength, Abrams slump cone, and the standard test method for specific gravity, absorption, and voids in hardened concrete (ASTM C642-90). The saturation method used for the determination of the density and porosity has been the vacuum saturation instead of boiling, because it seems to be a more efficient method [31]. As it can be seen in the table, all the concretes are of standard resistant class (30-40 MPa).

The concrete was cast in cylinders of $10 \mathrm{~cm}$ diameter and $12 \mathrm{~cm}$ height. The cylinders were kept in humidity chamber $\left(20^{\circ} \mathrm{C}\right.$ and 95\% RH) for 24 hours. After one day the samples were demoulded, and cut into slices of 3 or $4 \mathrm{~cm}$ thick. Also standardised samples for the determination of the compressive strength (mechanical resistance) were prepared.

These slices were kept completely submerged in a $\mathrm{Ca}(\mathrm{OH})_{2}$ solution until the complete maturation of the concrete (1 year).

\section{2.- Moisture conditioning.}

Once the age of 1 year was reached samples were prepared to get the desired saturation degree. The procedure used is based on the RILEM recommendation TC-116 [32], and has been described elsewhere [33]. The first step consists in obtaining the basic drying data: drying curves and total water absorption of the concretes. For that purpose the samples are saturated with distilled water [34], and then kept in air in an oven at $50{ }^{\circ} \mathrm{C}$ for 550 hours. The temperature was chosen to avoid changes in the pore network due to high temperature [35]. The mass of each sample was periodically measured to register the mass loss versus drying time. The result will permit the calculation of the mass loss necessary to achieve a fixed moisture saturation degree, as well as the approximate time necessary to reach that saturation degree. 
Each sample was water saturated, then dried to the desired moisture saturation degree, calculated using the previously presented methodology. Once the desired mass was reached the samples were introduced in empty hermetic recipients and once closed they were put inside the oven at $50^{\circ} \mathrm{C}$. This temperature accelerates the redistribution and equilibration of the moisture content inside the sample. The time for the redistribution was chosen according to the recommendations of Parrott [35], and varied from 3 days for saturation degree of $90 \%$ to more than 20 days for the concrete type 3 and a saturation degree of 18\%. The complete list of times necessary for the redistribution of the moisture is given in Table 3, as well as the constant water saturation degree (SD) achieved after the redistribution stage.

Each sample, once the equilibration time was finished, was left inside the hermetic recipient closed for 48 hours to reach the room temperature, as suggested by the RILEM recommendation [32].

The relative humidity reached in the container was measured using a hygrometer Vaisala MI70 and the samples were kept in big containers with the same relative humidity as that determined in their equilibrium. The relative humidity was achieved using saline or glycerine solutions, prepared using the corresponding standard [36] until their utilization for the characterization.

\section{3.- Mercury intrusion porosimetry measurements.}

The pore structure of the matures concretes was determined using the mercury intrusion porosimetry (MIP). The technique is well known, and has been widely described [20, 37]. The porosimeter employed was the AUTOPORE IV 9500 by Micromeritics that permits the determination of the volume of pores whose accessible diameter is between $5 \mathrm{~nm}$ and $0.9 \mathrm{~mm}$. The total porosity, the mercury 
retention after the experiment, and the volume of pore on each decade measured were determined for each concrete. For each concrete type two samples were tested.

\section{4.- Impedance Spectroscopy.}

The impedance spectra were obtained using an Agilent 4294 Impedance Gain/Phase analyzer. The equipment has a maximum resolution of $10^{-15} \mathrm{~F}$, and can measure from $10^{-14}$ to $0.1 \mathrm{~F}$. Even though the equipment allows the measurement in a frequency range from $40 \mathrm{~Hz}$ to $110 \mathrm{MHz}$, the spectra have been taken in the range from $100 \mathrm{~Hz}$ to $100 \mathrm{MHz}$.

The measurements have always been made using two electrode configurations. For each saturation degree the samples were measured with the two electrodes in contact with the sample (contact measurement), and interposing a polymer sheet between the sample and each electrode (non-contact measurement) [20]. In Fig. 1 there is a scheme for each configuration. The impedance spectrum of the polymeric sheets was also measured and it was subtracted from the overall impedance, to get only the impedance of the sample. The measurements are taken separately and made for the same frequency range and the same frequency values. For each frequency, the value of the impedance corresponding to the isolating films is subtracted from the value of the overall impedance, as a simple subtraction of complex numbers. This fact minimizes the fringe effects, since there is a subtraction of two impedances, where the fringe effects are similar. Fig. 2.a shows the impedance spectra for a sample with two saturation degrees obtained measuring the sample in contact with the electrodes. Fig. 2.b shows the Cole-Cole diagrams [29] (capacitance representation) of the same sample obtained from the non-contacting measurement. 
The impedance spectra obtained were fitted with previously established equivalent circuits for this kind of materials which are shown on Fig. 2 for each electrode sample configuration used. The equations corresponding to each circuit are shown in Eq. 1 and 2.

$$
\begin{aligned}
& Z(\omega)=\frac{Z_{1} \cdot Z_{2}}{Z_{1}+Z_{2}} \text { where }\left(Z_{1}=\frac{R_{1}}{1+\left(j \omega R_{1} \cdot C_{1}\right)^{\alpha_{1}}} \text { and } Z_{2}=R_{2} \cdot\left(1+\left(j \omega R_{2} \cdot C_{2}\right)^{-\alpha_{2}}\right)\right) \\
& C(\omega)=C_{1}+\frac{C_{2}}{\left(1+\left(j \cdot \omega \cdot R_{2} \cdot C_{2}\right)^{\alpha}\right)^{\beta}}
\end{aligned}
$$

The first equation is used for the calculation of the electric parameters of the measurement using contact electrode-sample. The electrical parameters have already been described [20,30], resistances $R_{1}$ and $R_{2}$, capacitances $C_{1}$ and $C_{2}$, and dispersion factors $\alpha_{1}$ and $\alpha_{2}$. Equation number 2 is called the HavriliakNegami equation and the meaning of the parameters has also been described and in deep discussed [20, 23, 30]. The electrical data are calculated by fitting the experimental results to the proposed equivalent circuit. The values of these parameters are used for the study of the microstructure. Three measurements have been made on different samples for every material tested and every saturation degree. The results presented will be the average of the measurement, including the error bar. Since the electrodes and the cables were always the same, samples were tested at laboratory temperature, that did not change much, and the same calibration was made for every set of measurements, the deviation on the measurements could be assigned only to the inhomogeneity of the material. 


\section{3.- Results and discussion}

The main results have been obtained using the impedance spectroscopy. However the results of mercury intrusion porosimetry are very helpful for the discussion of the overall results, and will be shown first.

\subsection{Microstructural characterization of concretes.}

The total porosity has been determined using the standard ASTM C642-90. As it can be seen in Table 2 the concrete type 1 shows higher water absorption after immersion, and after immersion and boiling, as could be expected due to the higher w:c ratio used for this concrete type. The values are lower for concrete type 2, and the lowest for concrete type 3. The same tendency has been observed for the volume of permeable pores measured. However the value for the bulk and apparent density does not change much from one sample to another.

The results of the MIP determinations are shown in Fig. 3. It shows the total intrusion volume per gram of sample, which indicates the total porosity of the sample and also shows the distribution of the total porosity in the different ranges for the diameters of the pores. As it can be seen, the total porosity shows the same tendency as the ASTM C642 test, the concrete type 1, with a higher w:c ratio has the highest porosity, while the concrete type 3 shows the lowest porosity of the series, as expected from the lowest w:c ratio.

More important than this fact is the pore distribution for each concrete. As it can be also seen in Fig. 3 as the w:c ratio decreases, the contribution of the smaller pores, with diameter below $100 \mathrm{~nm}$, increases. The volume of pores with diameter among $1 \mu \mathrm{m}$ and $100 \mathrm{~nm}$ decreases, and the volume of pores with bigger diameter remains more or less constant, with independence of w:c ratio. This 
means that the lower w:c ratio produces a higher amount of small pores, and less pores in the diameter range from $1 \mu \mathrm{m}$ to $100 \mathrm{~nm}$.

\section{2.- Impedance spectroscopy results.}

As it was mentioned before, in the experimental section, the measurements were taken using both the contacting and non-contacting methodologies. As it can be seen in Fig. 2 both methodologies give results for the capacitances $C_{1}$ and $C_{2}$, and the resistance $R_{2}$, while the resistance $R_{1}$ can only be obtained from the contacting method. These parameters have been shown to be dependent on the dimensions of the measured sample, especially on the thickness of the sample [20, 30]. Since not all the samples had the same thickness, and in order to compare the obtained values it is necessary to normalize the parameters to the thickness of the sample. The capacitance $\mathrm{C}_{1}$ has been proved to be a dielectric capacitance, and has an inverse relationship with the thickness. The rest of the parameters increase as the thickness of the sample does. So, the parameters studied here will be $\mathrm{C}_{1} \cdot \mathrm{d}$, $\mathrm{C}_{2} / d, \mathrm{R}_{1} / \mathrm{d}$, and $\mathrm{R}_{2} / \mathrm{d}$, being $\mathrm{d}$ the thickness of the sample. Three samples were tested for each condition, and the average results are presented.

The evolution of the parameters does not depend on the experimental setup used. Fig. 4 shows the evolution of the capacitance $C_{1} \cdot d$ and the resistance $R_{2} / d$, for all the samples of concrete type 1 . The result is equivalent for the rest of concrete types. The evolution of the parameters is very similar for both setups, and the values of the resistance are very similar. The values for the capacitance are higher when they are obtained using the contacting setup. This result has already been reported for cement pastes [20], even though the samples were thinner, and the differences were associated to the runaway capacitance, that is eliminated in the non-contacting measurements. Since the tendencies obtained for the parameters 
that are common for both methods are very similar, and the sensitivity of the fitting of the measurements made using the contacting method is lower, the parameters $C_{1}, C_{2}$, and $R_{2}$ will be discussed based on the results of the noncontacting method.

Fig. 5 shows the influence of the saturation degree of the sample on the resistance $\mathrm{R}_{1}$. This resistance has been proved to be representative of the total volume of pores that connect both sides of the sample.

In saturation condition the value of the resistance of the samples is inverse proportional to their porosity. The bigger resistance is for concrete $\mathrm{H} 3$, and the lower resistance for concrete type H1. The value of the resistance increases exponentially as the saturation degree decreases for every concrete type. Concrete types 1 and 2 follow the same tendency with the saturation degree. Concrete type 3 (H3) shows a change in the tendency below $45 \%$ percentage of saturation, with a resistance always higher than for the rest of the concrete types. For a percentage of saturation below $45 \%$ the value of the resistance for concrete type 3 is lower than for concretes H1 and H2. This result could be due to the more refined microstructure of this kind of concrete, with a bigger amount of pores below 100 nm diameter, as the MIP results show.

The rest of the parameters have been obtained from the non-contacting measurements, as explained before.

The results for the resistance $\mathrm{R}_{2}$ are shown in Fig. 6 . The tendency is equal to the observed for the resistance $\mathrm{R}_{1}$. In fact, in the non-contacting measurements both resistances will be included in the value of $R_{2}$. The only difference is that for $R_{2}$, the evolution of the resistance with the saturation degree is exponential and it is higher when the concrete porosity is lower, as expected for every resistance. For this parameter the influence seems to be higher from the total porosity than from 
the pore size distribution, perhaps because these pores are not directly opened to the surface of the sample (and include the occluded pores) and their drying kinetics could be more influenced for the total volume of pores. The opened pores, represented by $\mathrm{R}_{1}$ are easier to dry, and the drying kinetics will be influenced by the pore size present. The occluded pores, and not accessible pores, represented by R2 are more difficult to dry, and their drying, looking at the impedance spectroscopy results, is influenced by the total porosity.

Fig. 7 shows the evolution of the normalized capacitance $C_{1} \cdot d$ with the saturation degree of the samples. As it can be seen there are no important changes with the saturation degree of the samples in the value of the capacitance. This is in agreement with the nature of this parameter that has been reported to be related to the solid fraction of the samples [20, 21, 30]. The saturation degree does not influence the solid fraction of the sample, as reflected by the evolution of the capacitance $\mathrm{C}_{1}$.

The value of the capacitance $\mathrm{C}_{1}$ is related to the solid fraction in the sample. It remains constant with the saturation degree, but can vary from one concrete type to another. The results of mercury intrusion porosimetry, and the ASTM C642 test say that the concrete type 1 is the most porous of all the concrete types studied, and the concrete type 3 is the less porous. With these results, the value of the capacitance $\mathrm{C}_{1}$ for concrete type 1 should be the lowest, and the values of this parameter for concrete type 3 should be the highest. The obtained result, as shown in Fig 7, is not in agreement with this hypothesis. The reason for this disagreement may come from two reasons, or the similar densities observed, as shown in Table 2, or the experimental setup. The dielectric capacitance $C_{1}$ should be measured using a flat infinite condenser. This means two electrodes separated by the concrete to be characterized, where the dimensions of the electrode are 
bigger than the thickness of the sample. In our case the electrodes used for the measurement were of $7 \mathrm{~cm}$ diameter, and the thickness of the samples was about 3 to $4 \mathrm{~cm}$. both dimensions are comparable and will influence the calculated values of the capacitance $\mathrm{C}_{1}$. However since the dimensions were similar for all the studied concrete types the variations of the capacitance $\mathrm{C}_{1}$ can be used to evaluate differences in the solid phase of the concrete samples.

This result is important because in the case of using this technique in a real structure, the electrodes will not be in any case much bigger than the structure dimension, but the technique will allow determining the changes that may occur in the solid phase as well.

The evolution of the capacitance $\mathrm{C}_{2}$ with the saturation degree of the samples is shown in Fig. 8. As it can be seen in that figure, the value of the capacitance remains approximately constant with independence of the saturation degree of the concrete sample, This parameter represents the amount of pore surface in contact with liquid [30]. According to the results obtained the pore surface in contact with liquid does not vary. This result can mean that the electrolyte present in the pores is redistributed, if the necessary time is given. This result has been proposed by some researchers, [38] but had not been yet confirmed. This result also confirms that the times proposed by Parrott are enough to ensure the redistribution of the liquid present in the concrete homogenously over the pore surface.

The results of the dispersion factors also can be useful to corroborate this result. The results are shown in Fig. 9. The value of these parameters vary from 0 to 1 , and the physical meaning is 1 means no dispersion, and 0 total dispersion. As it has been proved the symmetrical dispersion factor $\alpha$ represents the wideness of the pore families present in the porous structure, and the asymmetrical dispersion factor $\beta$ shows the presence of pores of diameters very different from each other 
[30], what means the presence of different pore families. As it can be seen in Fig. 9 the value of the asymmetrical dispersion factor is lower for all concrete types at a $100 \%$ saturation degree. This result could be expected, because of the status of total saturation of the pores, and there is a contribution to the impedance spectrum of pores with size very different one to each other as shown in Fig. 10.a. As the saturation degree decreases, the surface of most pores is still in contact with electrolyte, but not all the pores remain full of liquid. The dimension of the pore that can conduct will decrease, initially for the bigger pores. This fact can conduct to the situation reflected in Fig 10.b, in that situation all the pores have similar dimensions for the liquid phase that contain. In that situation the importance of the asymmetrical dispersion factor decreases (value closer to 1), because there are no big differences in effective pore dimension, and increases the importance of the symmetrical dispersion factor because there will be small differences in the effective pore dimensions. This tendency continues until the saturation degree of $60 \%$ or $45 \%$. At these values the asymmetrical dispersion factor is very close to 1 , and this could mean that the conducting surface of each pore is approximately equal to the dimension of the smallest pores (Fig 10.b). At lower saturation degrees the value of the asymmetrical dispersion factor gets more importance, and values lower than 1 , may be due to the higher difficulty to dry small pores [40] (see Fig 10.c), and the difference of the thickness of the continuous path formed over the pore walls is thicker for the smaller pores, and as a consequence the asymmetrical dispersion factor decreases because important differences in the effective pore dimensions appear again.

In this situation the pure diffusion of chlorides will be very difficult, because they are forced to diffuse through the water continuous layer that will be very thin for low saturation degrees. 
In addition to that, the impedance spectroscopy technique seems to be suitable to study in a non-destructive way the water content, and the water distribution in real structures.

\section{4.- Conclusions}

With the results previously presented and discussed the following conclusions can be extracted:

- The impedance spectroscopy is a non-destructive technique that can be used to study the distribution of water in partially saturated concrete samples.

- The solid phase does not vary under drying processes, but the determination of the solid fraction using this technique is not very suitable for samples with thickness similar to the electrode diameter.

- When there is enough time, in conditions of partial saturation of concrete samples, the water is redistributed forming a continuous path all over the pore walls.

- The times given for the water redistribution used in this work seem to be enough to achieve the moisture redistribution inside the sample.

\section{5.-Acknowledgements.}

Authors would like to thank the Spanish "Ministerio de Economía y Competitividad” former “Ministerio de Ciencia e Innovación” for the financial support through projects BIA 2010 -20548 and BIA 2011-25721.

\section{References}

1 Cyr, M. Rivard, P. Labrecque, F. Reduction of ASR-expansion using powders ground from various sources of reactive aggregates. Cem Concr. Comp. 31(2009) 438-446. 
2 De Oliveira, M.B. Vazquez, E. The influence of retained moisture in aggregates from recycling on the properties of new hardened concrete. Waste Management 16(1-3) (1996) 113-117.

3 López, W. Gonzalez, J.A. (1993) Influence of the degree of pore saturation on the resistivity of concrete and the corrosion rate of steel reinforcement. Cem. Concr. Res 23; 368-376

4 Giarma, C. Estimation of carbonation depth based on Hygrothermal calculations. Aci Mat Journal 108(2) (2011) 209-218.

5 Climent, M.A. de Vera, G. López, J.F. Viqueira, E. Andrade, C. A test method for measuring chloride diffusion coefficients through nonsaturated concrete. Part I: The instantaneous plane source diffusion case. Cem. Concr. Res. 32 (2002) 1113-1123.

6 de Vera, G. Climent, M.A. Viqueira, E. Antón, C. Andrade, C. A test method for measuring chloride diffusion coefficients through partially saturated concrete. Part II: The instantaneous plane source diffusion case with chloride binding consideration. Cem. Concr. Res. 37 (5) (2007) 714-724.

7 Guimarães, A.T.C. Climent, M.A. de Vera, G. Vicente, F.J. Rodrigues, F.T. Andrade, C. Determination of chloride diffusivity through partially saturated Portland cement concrete by a simplified procedure. Constr. Build. Mater., 25 (2) (2011) 785-790.

8 Rucker-Gramm, P. Beddoe, R.E. Effect of moisture content of concrete on water uptake. Cem Concr. Res. 40 (2010) 102-108.

9 Parrott, L. A review of methods to determine the moisture conditions in concrete. Performance criteria for concrete Durability. Ed. Kropp, J. and Hilsdorf, H.K. E\&FN Spon. London (1995) 294-321.

10 Klysz, G. Balayssac, J.P. Laurens, S. Spectral analysis of radar surface waves for nondestructive evaluation of cover concrete. NDT\&E international 34(2004) 221-227.

11 Laurens, S. Balayssac, J.P. Rhazi, J. Klysz, G. Arliguie, G. Non-destructive evaluation of concrete moisture by GPR: experimental study and direct modeling. Materials and Structures/Materiaux et Constructions, 38 (283) , (2005) 827-832

12 Larsen C.K. Sellevold, E.J. Askeland, F.Østvik, J.M. Vennesland, Ø. Electrical resistivity of concrete part II: influence of moisture content and temperature. 2nd int. symposium on advances in concrete through science and engineering. Canada (2006)

13 Andrade, M.C. Bolzoni, F. Fullea, J. Analysis of the relation between water and resistivity isotherms in concrete. Mat and corr. 62(2) (2011) 130-138

14 Carr-Brion, K. (1986) Moisture Sensors in Process Control, Elsevier, pp. 122

15 Sbartaï, Z.M. Laurens, S. Balayssac, J.-P. Ballivy, G. Arliguie, G. Effect of concrete moisture on radar signal amplitude, ACI Mat. Journal. 103(6). (2006) 419-426

16 Schmugge, T.J., Jackson, T.J. and McKim H.L. (1980) Survey of methods for soil moisture determination. Water Resources Research, Vol. 16, No. 6, pp. 961-979.

17 Cornell, J.B. and Coote, A.T. (1972) The application of an infrared absorption technique to the measurement of moisture content of building materials. Journal of Applied Chem. Biotechnology, Vol. 22, pp. 455-463. 
18 Castellote, M., Alonso, C., Andrade, C., Turrillas, X., Campo, J.. Composition and microstructural changes of cement pastes upon heating, as studied by neutron diffraction. Cem. Concr. Res. 34, 1633-1644 (2004)

19 Baroghel-Bouny, V., Kinomura, K., Thiery, M., Moscardelli, S. Easy assessment of durability indicators for service life prediction or quality control of concretes with high volumes of supplementary cementitious materials. Cem. Concr. Comp. 33(8) 832-847 (2011)

20 M. Cabeza, P. Merino, A. Miranda, X.R. Novoa, I. Sanchez. Impedance spectroscopy study of hardened Portland cement paste. Cem. Concr. Res. 32 881-891 (2002)

21 I. Sánchez, X.R. Nóvoa, G. de Vera, M.A. Climent. Microstructural modifications in Portland cement concrete due to forced ionic migration tests. Study by impedance spectroscopy. Microstructural modifications in Portland cement concrete due to forced ionic migration tests. Study by impedance spectroscopy. Cem. Concr. Res. 38(7) 10151025(2008)

22 Sanchez, I., Lopez, M.P., Ortega, J.M., Climent, M.A. Impedance Spectroscopy: an efficient tool to determine the non steady state diffusion coefficient in building materials. Mat and Corr. 62(2), 139-145 (2011)

23 Sánchez, I., Sánchez, M. Climent, M.A., Alonso, C. Impedance Spectroscopy to characterise microstructural changes in liquid and solid phases of mortars exposed to high temperature. 2nd International RILEM Workshop on Concrete Spalling due to Fire Exposure, 43-51 (2011)

24 M. Cabeza, P. Merino, X.R. Novoa, I. Sanchez. Electrical effects generated by mechanical loading of hardened Portland cement paste. Cem. Concr. Comp. 25. 351-356. (2003)

25 E.Barsoukov, J.R. McDonald, Impedance Spectroscopy. Theory, Experiments, and Applications, 2nd Ed., Willey Interscience, New Jersey, USA (2005)

26 B.J.Christensen, R.T. Coverdale, R.A. Olson, S.J. Ford, E.J. Garboczi, H.M. Jennings, T.O. Mason, Impedance spectroscopy of hydrating cement-based materials: measurement, interpretation and application, J. Am. Ceram. Soc., 77 (1994) 2789-2804.

27 R.T. Coverdale, B.J. Christensen, T.O. Mason, H.M. Jennings, E.J. Garboczi, Interpretation of the impedance spectroscopy of cement paste via computer modelling: Part II. Dielectric response, J. Mater. Sci., 29 (1994) 4984-4992.

28 Keddam, M. Takenouti, H. Nóvoa, X.R. Andrade, C. Alonso, C. Impedance measurements on cement paste, Cem. Concr. Res. 27 (1997) 1191- 1201.

29 Andrade, C. Blanco, V.M. Collazo, A. Keddam, M. Nóvoa, X.R. Takenouti, H. Cement paste hardening process studied by impedance spectroscopy, Electrochim. Acta 44 (1999) $4313-4318$.

30 M. Cabeza, M. Keddam, X.R. Nóvoa, I. Sánchez, H. Takenouti, Impedance spectroscopy to characterize the pore structure during the hardening process of Portland cement paste, Electrochim. Acta, 51 (2006) 1831-1841. 
31 Safiuddin, Md. Hearn, N. Comparison of ASTM saturation techniques for measuring the permeable porosity of concrete; Cem. Concr. Res. 35 1008-1013 (2005)

32 RILEM TC 116-PCD: Permeability of Concrete as a Criterion of its Durability. Preconditioning of Concrete Test Specimens for the Measurement of Gas Permeability and Capillary Absorption of Water. Materials and Structures Vol. 32 (3), pp 174-179 (1999).

33 Antón, C.; Climent, M.A.; de Vera, G,; Sánchez, I.; Andrade, C. An improved procedure for obtaining and maintaining well characterized partial water saturation states on concrete samples to be used for mass transport tests. Materials and Structures/Materiaux et Constructions. In press. DOI 10.1617/s11527-012-9981-4

34 ASTM Standard C 1202-97, Standard test method for electrical indication of concrete's ability to resist chloride ion penetration, Annual Book of ASTM Standard Section 4, Vol 04.02 (2000).

35 Parrott, L.J. Moisture conditioning and transport properties of concrete test specimens Materials and Structures Vol. 27 (8) pp 460-468 (1994).

36 Deutsche norm Din50 008 Part 1. Atmospheres and their technical application; Standard atmospheres over aqueous solutions; Saturated salt solutions, glycerol solutions.

37 S. Diamond, Mercury porosimetry. An inappropriate method for the measurement of pore size distributions in cement-based materials, Cem. Concr. Res., 30 (2000) 1517-1525.

38 Pedeferrri, P. Bertolini, L. La Durabilità del Calcestruzzo Armato. McGraw Hill Italia, p 27. (2000)

39 Parmon, V.N. Derivation of the classical Kelvin (Thomson) formula for equilibrium saturated vapor pressure over a drop of a liquid. Russian Journal of Physical Chemistry A, 73 (1) , pp. 7-11 (1999) 

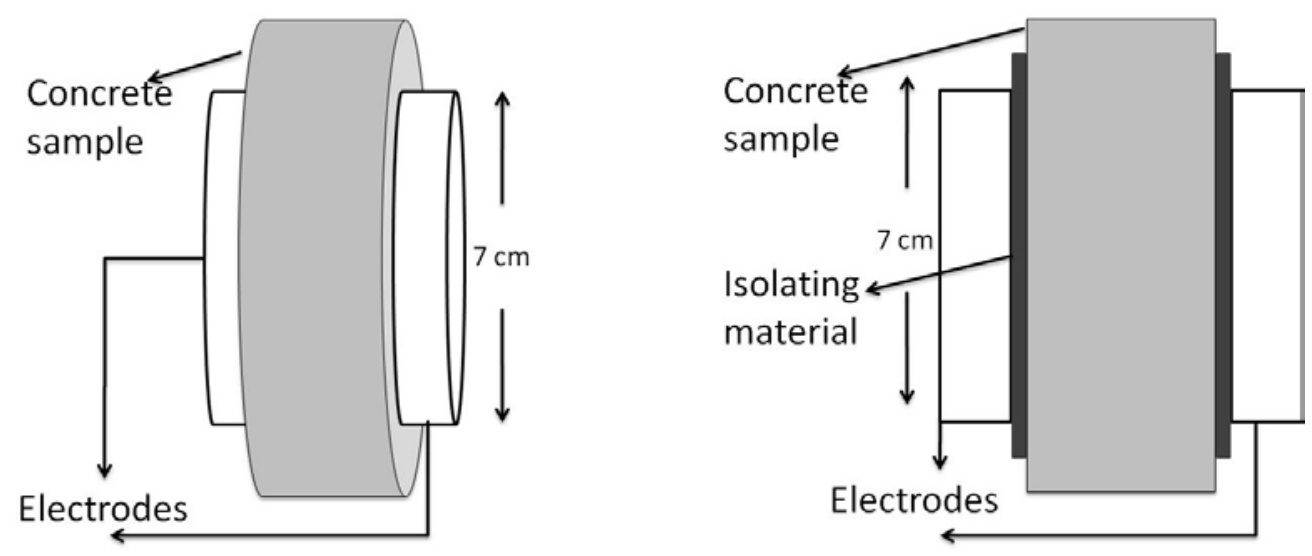

Figure 1. Schematic of the electrode-concrete sample configurations used for the obtention of the impedance spectra of the materials.
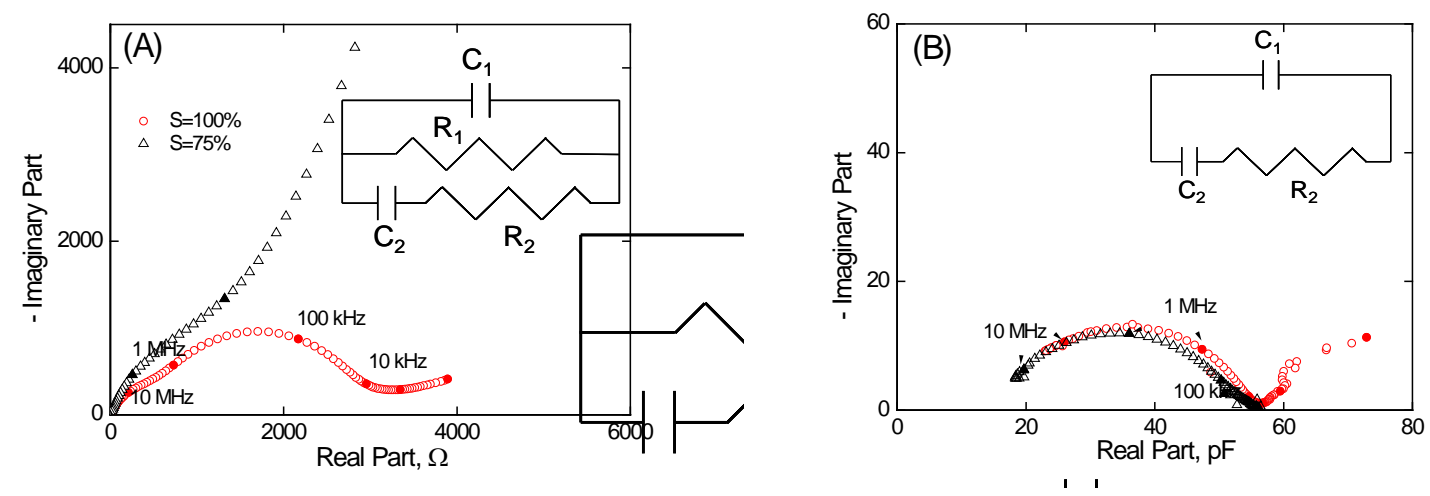

Figure 2. : Impedance spectra for a sample of concrete type 3, for a sample with a degree of saturation of $100 \%$, and for a saturation degree of $75 \%$. The sample thickness was of $3.06 \mathrm{~cm}$. (A) corresponds to the contact method, while (B) corresponds to the Cole-Cole representation of the sample using the polyester sheet between electrode and sample. 


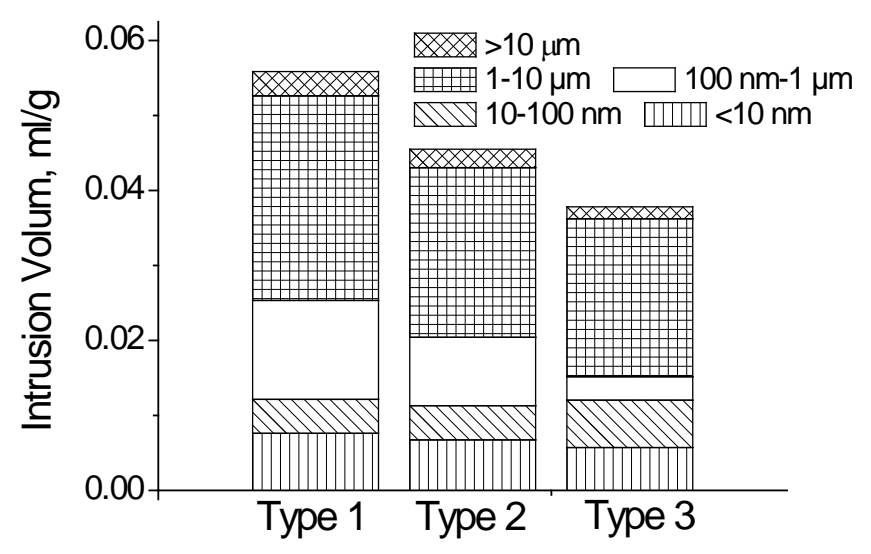

Figure 3. Distribution of the total porosity on pore diameter ranges, for the three types of concrete studied. The total range of pore diameters studied has been divided in 5 regions, of at least one decade of pore ranges in each region.
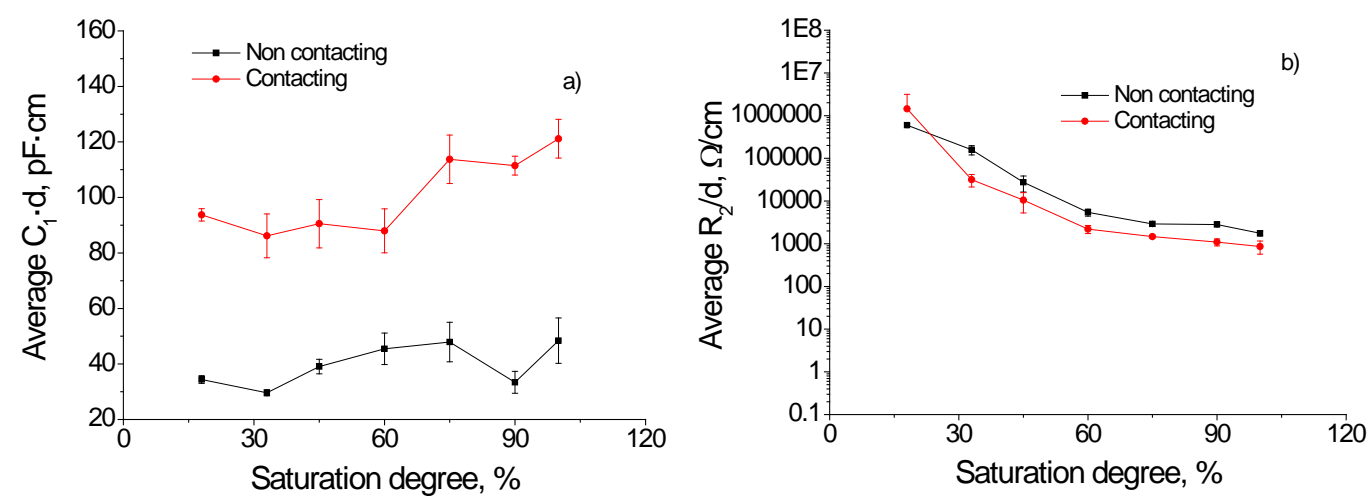

Figure 4. : Comparison of the tendencies of the values of the average normalized capacitance $C_{1}$ and the average normalized resistance $R_{2}$, obtained using the contacting and non-contacting setups as a function of the saturation degree of the sample. 


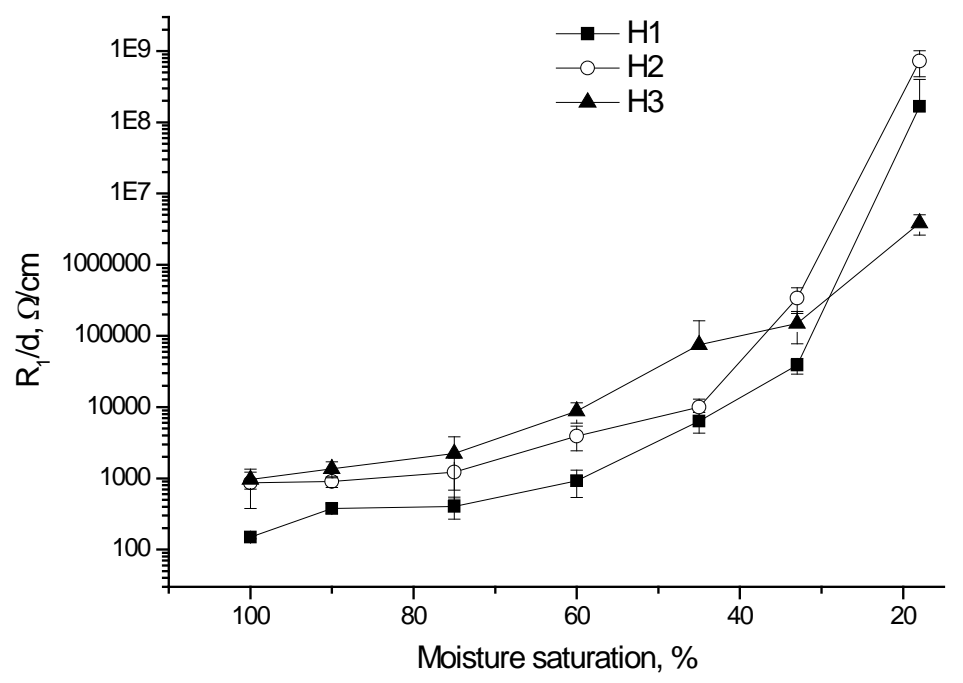

Figure 5. Evolution of the resistance $\mathrm{R}_{1}$ with the degree of saturation. Measurements with contact electrode-sample.

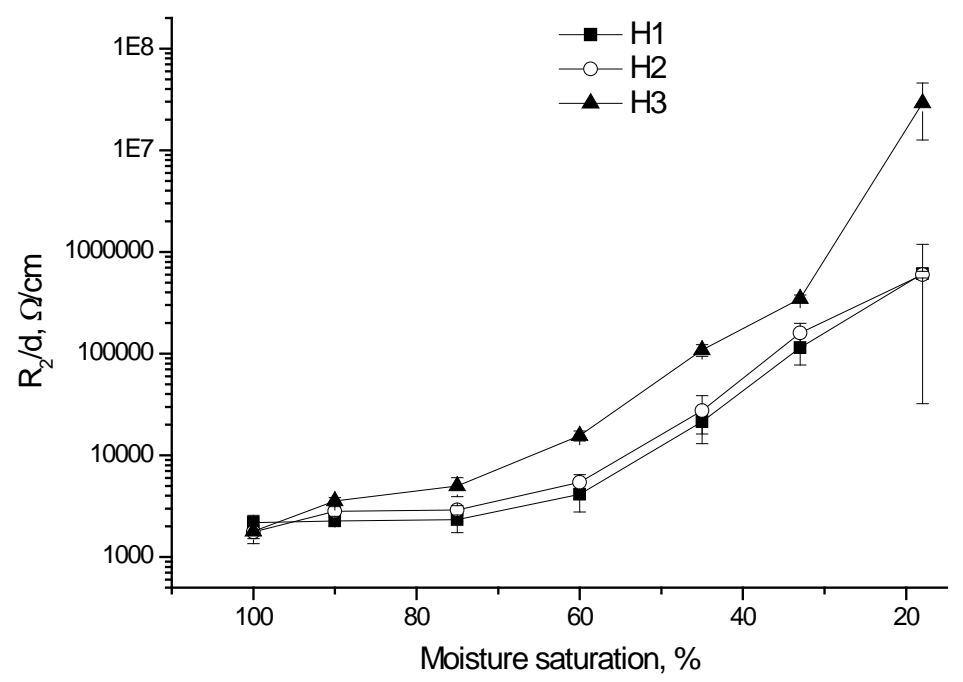

Figure 6. Evolution of the resistance $\mathrm{R}_{2}$ with the degree of saturation. Measurements without contact. 


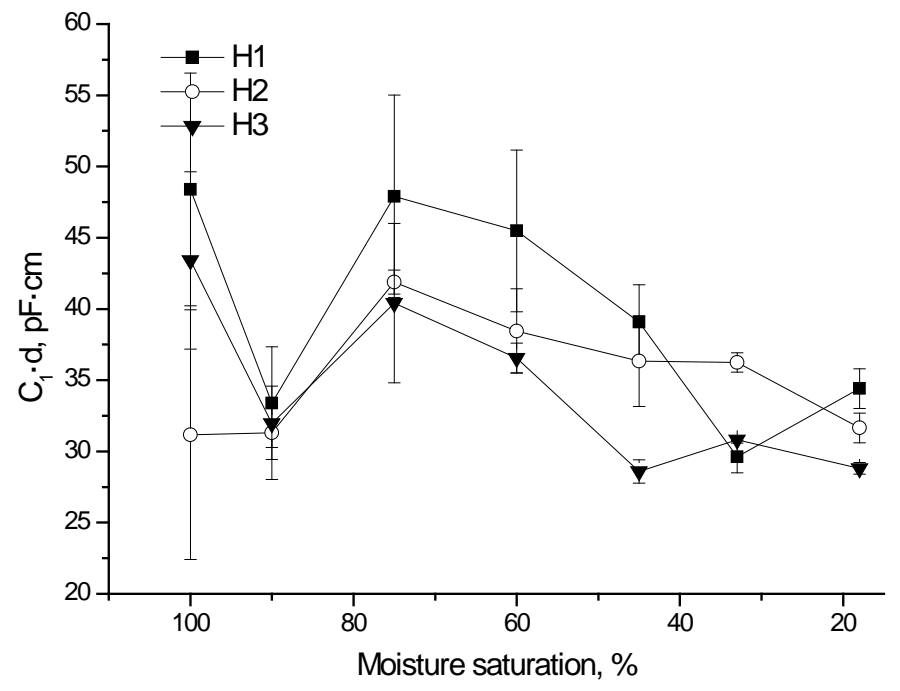

Figure 7. Evolution of the high frequency capacitance, $\mathrm{C}_{1}$, with the degree of saturation. Measurements without contact.

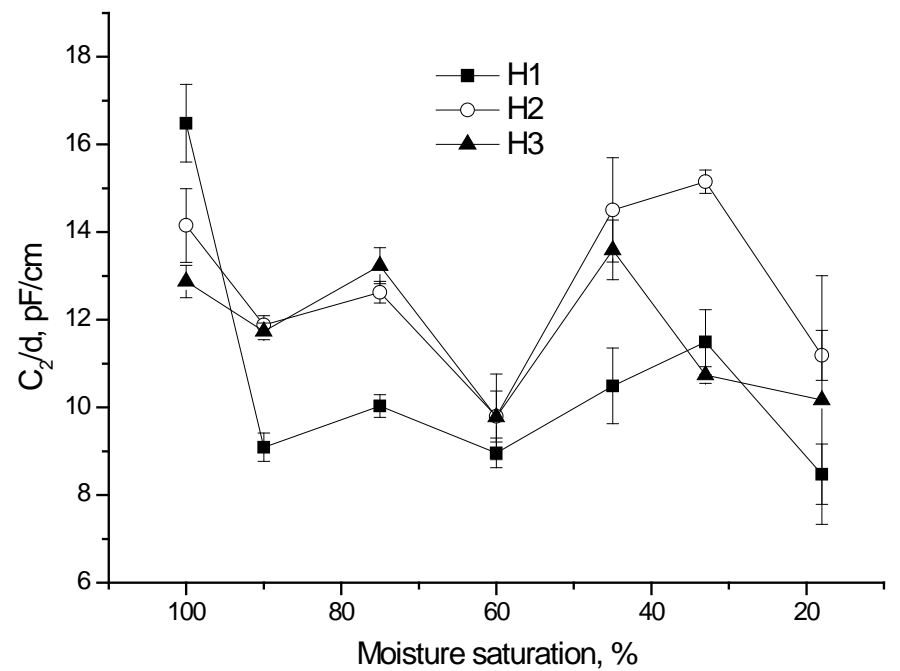

Figure 8. Evolution of the low frequency capacitance $C_{2}$ with the degree of saturation. Measurements without contact. 

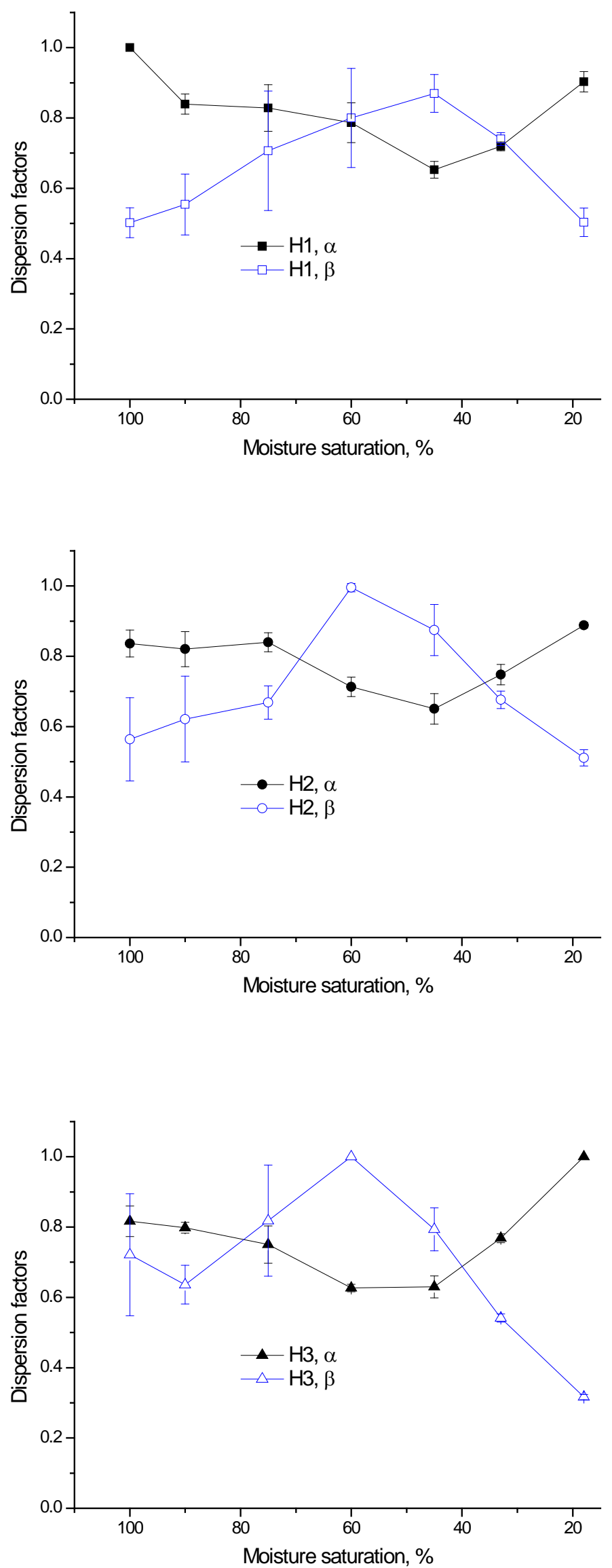
Figure 9. Evolution of the dispersion parameters, $\alpha$ and $\beta$, with the degree of saturation. Measurements without contact.
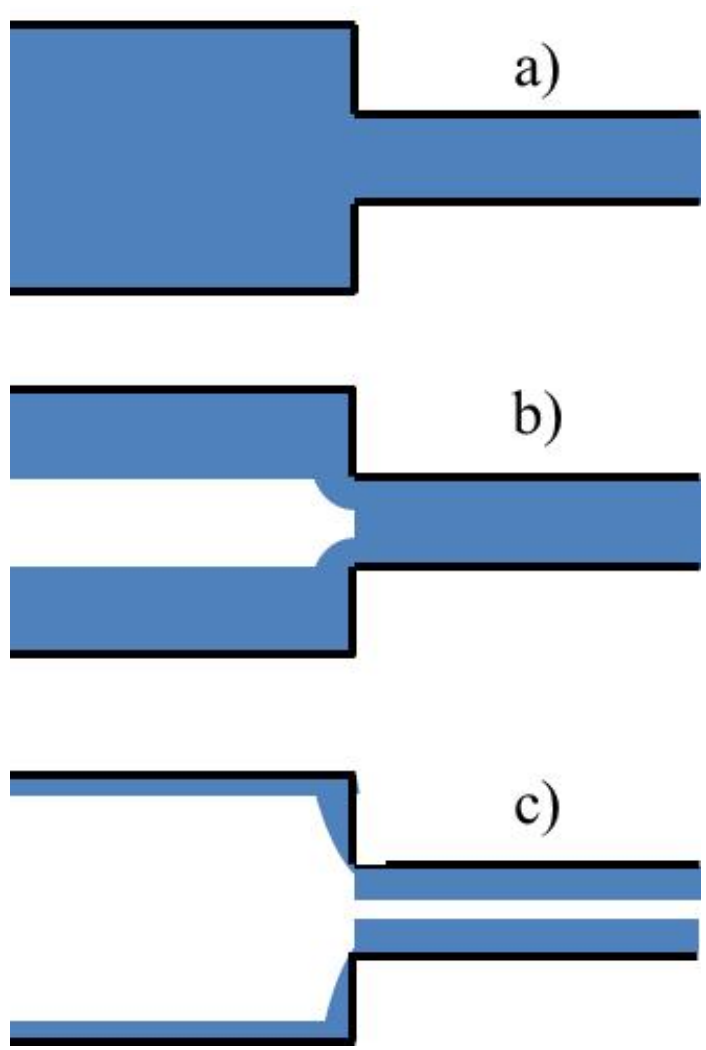

Figure 10. Scheme for the evolution of the moisture content in the pores as the drying of the sample progresses

Table 1 :dosage used for each concrete specimens

\begin{tabular}{|c|c|c|c|}
\hline & PC60 (H1) & PC50 (H2) & PC38 (H3) \\
\hline Cement $(\mathrm{Kg})$ & 350 & 350 & 450 \\
\hline Sand $\left(\mathrm{Kg} / \mathrm{m}^{3}\right)$ & 630.3 & 662.8 & 628 \\
\hline Gravel 4/6 (Kg/m $\left.\mathrm{m}^{3}\right)$ & 465.5 & 489.5 & 523 \\
\hline Gravel 6/12 (Kg/m $\left.\mathrm{m}^{3}\right)$ & 679 & 714 & 637 \\
\hline Water/cement ratio & 0.6 & 0.5 & 0.38 \\
\hline Plasticizer (\%) & 0.4 & 1.4 & 1.5 \\
\hline
\end{tabular}


Table 2 : results of the standard test method for Abram's slump cone, compressive strength, specific gravity, absorption, and voids in hardened concrete (ASTM C642-90)

\begin{tabular}{|c|c|c|c|}
\hline Concrete & $\mathbf{1}$ & $\mathbf{2}$ & $\mathbf{3}$ \\
\hline Abrams' slump cone (cm) & 15 & 17.5 & 20 \\
\hline Av. Compr. Strength. & 31.3 & 40.3 & 40.2 \\
\hline Absorption after immersion (\%) & 7.0 & 5.4 & 4.5 \\
\hline Absorption after immersion and boiling(\%) & 7.1 & 5.6 & 4.6 \\
\hline Bulk sp gr, dry (g/cm $\left.{ }^{3}\right)$ & 2.18 & 2.23 & 2.29 \\
\hline Bulk sp gr after immersion (g/cm $\left.{ }^{3}\right)$ & 2.34 & 2.35 & 2.39 \\
\hline Bulk sp gr after immersion and boiling $\left(\mathrm{g} / \mathrm{cm}^{3}\right)$ & 2.34 & 2.36 & 2.39 \\
\hline Apparent sp gr (g/cm $\left.{ }^{3}\right)$ & & & \\
\hline Volume of permeable pore space $\left(\mathrm{voids}^{\prime}\right)(\%)$ & 15.6 & 12.6 & 10.5 \\
\hline
\end{tabular}

Table 3 : Saturation degree aimed and achieved after equilibration in the hermetic chambers used for the redistribution of the moisture.

\begin{tabular}{|c|c|c|c|}
\hline Concrete type & Aimed SD(\%) & $\begin{array}{c}\text { Equilibrium Chamber }\left(50^{\circ} \mathrm{C}\right) \\
\text { SD(\%) }\end{array}$ & Equilibrium time, \\
& 90 & 89.2 & 3 \\
\hline 1 & 90 & 83.7 & 3 \\
3 & 90 & 89.9 & 3 \\
\hline 1 & 75 & 75.2 & 3 \\
\hline
\end{tabular}




\begin{tabular}{|l|l|l|l|}
3 & 75 & 75.0 & 3 \\
\hline 1 & 60 & 59.6 & 4 \\
2 & 60 & 56.5 & 4 \\
3 & 60 & 59.0 & 4 \\
\hline 1 & 45 & 44.7 & 5 \\
2 & 45 & 45.1 & 8 \\
3 & 45 & 45.0 & 10 \\
\hline 1 & 33 & 32.9 & 9 \\
\hline 2 & 33 & 32.9 & 18 \\
\hline 1 & 18 & 16.3 & 14 \\
\hline 3 & 18 & 16.9 & 23 \\
\hline
\end{tabular}

Table 4 : mercury intrusion porosimetry results

\begin{tabular}{|c|c|c|c|}
\hline & Concrete 1 & Concrete 2 & Concrete 3 \\
\hline Total Porosity, \% & 12.33 & 10.17 & 8.59 \\
\hline Hg retention, \% & 46.79 & 55.17 & 59.53 \\
\hline
\end{tabular}

\section{Figure and table captions.}

Figure 1. Schematic of the electrode-concrete sample configurations used for the obtention of the impedance spectra of the materials.

Figure 2. Impedance spectra for a sample of concrete type 3, for a sample with a degree of saturation of $100 \%$, and for a saturation degree of $75 \%$. The sample thickness was of 3.06 $\mathrm{cm}$. (A) corresponds to the contact method, while (B) corresponds to the Cole-Cole representation of the sample using the polyester sheet between electrode and sample.

Figure 3. Distribution of the total porosity on pore diameter ranges, for the three types of concrete studied. The total range of pore diameters studied has been divided in 5 regions, of at least one decade of pore ranges in each region. 
Figure 4. Comparison of the tendencies of the values of the average normalized capacitance $\mathrm{C}_{1}$ and the average normalized resistance $\mathrm{R}_{2}$, obtained using the contacting and non-contacting setups as a function of the saturation degree of the sample.

Figure 5. Evolution of the resistance $\mathrm{R}_{1}$ with the degree of saturation. Measurements with contact electrode-sample.

Figure 6. Evolution of the resistance $\mathrm{R}_{2}$ with the degree of saturation. Measurements without contact.

Figure 7. Evolution of the high frequency capacitance, $\mathrm{C}_{1}$, with the degree of saturation. Measurements without contact.

Figure 8. Evolution of the low frequency capacitance $\mathrm{C}_{2}$ with the degree of saturation. Measurements without contact.

Figure 9. Evolution of the dispersion parameters, $\alpha$ and $\beta$, with the degree of saturation. Measurements without contact.

Figure 10. Scheme for the evolution of the moisture content in the pores as the drying of the sample progresses

Table 1 :dosage used for each concrete specimens

Table 2 : results of the standard test method for Abram's slump cone, compressive strength, specific gravity, absorption, and voids in hardened concrete (ASTM C642-90)

Table 3 : Saturation degree aimed and achieved after equilibration in the hermetic chambers used for the redistribution of the moisture.

Table 4 : mercury intrusion porosimetry results 